\title{
Increased risk of dehiscence after tricuspid valve repair with rigid annuloplasty rings
}

\author{
Bettina Pfannmüller, MD, Torsten Doenst, MD, PHD, Katja Eberhardt, BS, Jörg Seeburger, MD, \\ Michael A. Borger, MD, PhD, and Friedrich W. Mohr, MD, PhD
}

Objectives: Surgical management of tricuspid valve regurgitation mainly consists of tricuspid valve annuloplasty, usually performed with implantation of a rigid ring or a flexible band.

\begin{abstract}
Methods: We performed a retrospective analysis on 820 patients who underwent tricuspid valve repair between March 2002 and July 2009 with either a flexible Cosgrove-Edwards band ( $=415$; Edwards Lifesciences LLC, Irvine, Calif) or a rigid Carpentier-Edwards Classic annuloplasty ring $(\mathrm{n}=405$; Edwards Lifesciences). Mean patient age was $69.2 \pm 9.5$ years, $54.1 \%$ were female, and average logistic EuroSCORE was $13.3 \% \pm 12.5 \%$. Concomitant procedures were performed in $94.6 \%$ of patients (mitral valve surgery, $80.6 \%$; aortic valve surgery, $28.2 \%$; coronary artery bypass grafting, $24.5 \%$; atrial fibrillation ablation, $44.5 \%$ ). One fifth of the operations were reoperative procedures. Follow-up was $94 \%$ complete, with mean duration of $21.0 \pm 19.0$ months.
\end{abstract}

\begin{abstract}
Results: Thirty-day mortality was 10.1\% (Cosgrove-Edwards, $11.9 \%$; Carpentier-Edwards, $8.4 \%$ ), and 5-year survival was $62.4 \%$ (Carpentier-Edwards, 64.7\%; Cosgrove-Edwards, 60.3\%). Postoperative echocardiography showed significant improvement in tricuspid valve function, with reduction in tricuspid regurgitation grade from $2.3 \pm 0.7$ to $0.7 \pm 0.7$, and no differences between groups. Use of a Carpentier-Edwards ring, however, was associated with significantly higher risk of dehiscence (Carpentier-Edwards, $8.7 \%$; Cosgrove-Edwards, $0.9 \%$; $P<.001$ ), almost exclusively at the septal leaflet portion of the annulus. Multivariate analysis identified annuloplasty type as independently predicting ring dehiscence (odds ratio, 10.7; 95\% confidence interval, 3.2-36.5; $P<.001)$. Patients with annuloplasty dehiscence had more residual tricuspid regurgitation on predischarge echocardiography than did patients without dehiscence $(1.4 \pm 0.63$ vs $0.7 \pm 0.6 ; P<.001)$. Ten patients underwent reoperation for recurrent tricuspid regurgitation, 4 with ring dehiscence. Five-year freedom from reoperation was $95.3 \%$ (Cosgrove-Edwards, 97.7\%; Carpentier-Edwards, 92.3\%).
\end{abstract}

Conclusions: Although both rigid and flexible systems provide acceptable early tricuspid valve repair results, use of a rigid ring increases risk of subsequent ring dehiscence. (J Thorac Cardiovasc Surg 2012;143:1050-5)

Surgical treatment of tricuspid regurgitation (TR) caused by annular dilatation mainly consists of tricuspid repair. Different techniques of tricuspid repair have been described, the main ones being the DeVega or Kay technique and ring annuloplasty with a rigid ring or a flexible band. ${ }^{1-11}$ As many as $20 \%$ of patients, however, have predischarge residual moderate or severe TR after tricuspid repair. ${ }^{2,10,12}$ The best long-term results after tricuspid repair have been reported with the implantation of annuloplasty devices, whereas the greatest recurrence of TR has been observed after the DeVega or Kay technique. ${ }^{2,12,13}$

\footnotetext{
From the Department of Cardiac Surgery, University of Leipzig Heart Center, Leipzig, Germany.

Disclosures: Authors have nothing to disclose with regard to commercial support. B.P. and T.D. contributed equally to this article.

Received for publication Dec 15, 2010; revisions received May 12, 2011; accepted for publication June 27, 2011; available ahead of print July 28, 2011.

Address for reprints: Bettina Pfannmüller, MD, University of Leipzig-Heart Center, Department of Cardiac Surgery, Strümpellstrasse 39, 04289 Leipzig, Germany (E-mail: bettina.pfannmueller@med.uni-leipzig.de).

0022-5223/\$36.00

Copyright (c) 2012 by The American Association for Thoracic Surgery doi:10.1016/j.jtcvs.2011.06.019
}

Because of the 3-dimensional dynamic shape of the tricuspid annulus, ${ }^{14-16}$ we have speculated that fixation of the annulus to a rigid ring may result in greater forces on the native annulus than would occur with a flexible band. We therefore compared our experiences with tricuspid repair with either a rigid planar ring (Carpentier-Edwards Classic annuloplasty ring; Edwards Lifesciences LLC, Irvine, CA) or a flexible band (Cosgrove-Edwards annuloplasty system; Edwards Lifesciences).

\section{MATERIALS AND METHODS}

Between March 2002 and July 2009, a total of 820 patients underwent tricuspid valve (TV) repair with a flexible Cosgrove-Edwards annuloplasty system or a rigid Carpentier-Edwards Classic tricuspid ring at our institution. Indications for TV surgery were symptomatic severe TR or else asymptomatic moderate TR or marked tricuspid annular dilation $(>4.0$ $\mathrm{cm}$ ) in the presence of other indications for cardiac surgery. Patients with infective endocarditis or organic disease of the TV (rheumatic, Ebstein, or carcinoid disease) were excluded from the study.

Preoperative, intraoperative, and postoperative parameters of all patients were prospectively entered into our patient data management system and then retrospectively analyzed. In addition, further chart review and information from preoperative and predischarge echocardiographic reports 


\section{Abbreviations and Acronyms \\ $\mathrm{TR}=$ tricuspid regurgitation \\ $\mathrm{TV}=$ tricuspid valve}

were gathered and analyzed. TR was calculated by measurement of vena contracta in a 4-chamber view. ${ }^{17}$

TV repair was performed with standard techniques, including bicaval cannulation and mild hypothermic cardiopulmonary bypass. All patients received an annuloplasty with either a Cosgrove-Edwards $(n=415)$ or a Carpentier-Edwards $(\mathrm{n}=405)$ device, depending on the surgeon's choice. Ethics approval was granted by the local ethics committee for this investigation.

\section{Follow-up}

Individual patient contact after discharge was performed by sending questionnaires to all patients annually after the operation. Patients who did not respond were contacted by telephone. If no further information about the patients was available, the family physicians were contacted. Follow-up was $94 \%$ complete, with a mean follow-up time of $21.0 \pm$ 19.0 months (range, 1 day-7.7 years).

\section{Statistical Evaluation}

Results are displayed in standard format, with continuous variables expressed as mean $\pm \mathrm{SD}$ and categoric data expressed as proportions. Cumulative survivals were calculated by Kaplan-Meier methods, and differences in follow-up were calculated with $95 \%$ confidence limits and compared by log-rank (Mantel-Cox) test. All statistical analyses were performed with the SPSS statistical package 15.0 (IBM Corporation, Armonk, NY).

\section{RESULTS}

Table 1 shows the demographic data of all patients, as well as those of the patients separated into the CosgroveEdwards and Carpentier-Edwards groups. Average age was $69.2 \pm 9.5$ years for the entire patient cohort, and more than half of patients were female. Average New York Heart Association class was 3.1 \pm 0.8 . Left ventricular function was normal in most patients, but mean pulmonary arterial pressures were elevated. More than half of the patients had atrial fibrillation, and most had hypertension. The only significant difference between the 2 surgical groups was the increased incidence of transvalvular permanent pacemaker leads in the Cosgrove-Edwards group.

Figure 1 shows a graphic illustration of the different operations in which TV repair was performed. Isolated TV repair was performed in about $10 \%$ of the cases. Most TV repairs were performed in conjunction with mitral valve repair or replacement. Concomitant ablation procedures were performed in almost half of the cases. Figure 1 also illustrates that the chosen annuloplasty type was not associated with the complexity of the procedure.

Table 2 shows perioperative characteristics. Operative time averaged 4 hours in all cases, with crossclamp time averaging 90 minutes and cardiopulmonary bypass time averaging 150 minutes. One fifth of patients required urgent or emergency surgery. Minimally invasive surgery through a right lateral minithoracotomy with femoral cannulation for cardiopulmonary bypass was used in 276 patients $(33.7 \%)$, with the remaining 544 patients $(66.3 \%)$ undergoing median sternotomy.

Figure 2 shows the severity of TR before $(A)$ and after $(B)$ TV repair. Most of the patients had moderate or severe TR preoperatively; however, $17 \%$ had mild or even no TR at the time of surgery. In these cases, the indication for TV repair was dilatation of the native tricuspid annulus. Postoperative TR was graded as none or trace in $47 \%$ of the total patient group, mild in $45 \%$, moderate in $7 \%$, and severe in $1 \%$.

Figure 3 shows the selected sizes for the CosgroveEdwards and Carpentier-Edwards groups as labeled by the manufacturer. There were no differences in the selected sizes between groups, with most patients receiving size 30 or $32 \mathrm{~mm}$.

In each group, 8 patients (Cosgrove-Edwards, 1.9\%; Carpentier-Edwards, $2.0 \% ; P=.8$ ) had a postoperative

TABLE 1. Demographic data

\begin{tabular}{|c|c|c|c|c|}
\hline & $\begin{array}{l}\text { All patients } \\
(\mathbf{n}=\mathbf{8 2 0})\end{array}$ & $\begin{array}{c}\text { Cosgrove-Edwards } \\
(n=415)\end{array}$ & $\begin{array}{c}\text { Carpentier-Edwards } \\
\text { Classic }(n=405)\end{array}$ & $P$ value \\
\hline Age $(y)$ & $69.2 \pm 9.5$ & $68.5 \pm 10.2$ & $69.8 \pm 8.8$ & .06 \\
\hline Male (no.) & $376(45.9 \%)$ & $188(45.3 \%)$ & $188(46.4 \%)$ & .78 \\
\hline $\begin{array}{l}\text { Preoperative New York Heart } \\
\text { Association functional class }\end{array}$ & $3.1 \pm 0.8$ & $3.0 \pm 0.7$ & $3.2 \pm 0.8$ & .01 \\
\hline Logistic EuroSCORE (\%) & $13.3 \% \pm 12.5 \%$ & $12.9 \% \pm 12.3 \%$ & $13.7 \% \pm 12.8 \%$ & .32 \\
\hline Left ventricular ejection fraction $(\%)$ & $57.4 \% \pm 15.8 \%$ & $58.3 \% \pm 15.7 \%$ & $56.3 \% \pm 15.8 \%$ & .14 \\
\hline Pulmonary arterial pressure $(\mathrm{mm} \mathrm{Hg})$ & $46.6 \pm 11.0$ & $47.7 \pm 15.9$ & $47.3 \pm 14.8$ & .72 \\
\hline Previous cardiac surgery (no.) & $135(21.8 \%)$ & $92(22.2 \%)$ & $87(21.5 \%)$ & .43 \\
\hline Atrial fibrillation (no.) & $500(61 \%)$ & $263(63.4 \%)$ & $237(58.5 \%)$ & .11 \\
\hline Hypertension (no.) & $644(78.5 \%)$ & $329(79.3 \%)$ & $315(77.8 \%)$ & .69 \\
\hline Diabetes mellitus (no.) & $252(30.7 \%)$ & $106(25.5 \%)$ & $146(36.0 \%)$ & .003 \\
\hline Permanent pacemaker (no.) & $85(13.7 \%)$ & $71(17.0 \%)$ & $43(10.4 \%)$ & $<.01$ \\
\hline
\end{tabular}

Data are mean \pm SD unless marked as number of patients. Cosgrove-Edwards, Cosgrove-Edwards annuloplasty system, Edwards Lifesciences LLC, Irvine, Calif; CarpentierEdwards Classic, Carpentier-Edwards Classic annuloplasty ring, Edwards Lifesciences. 


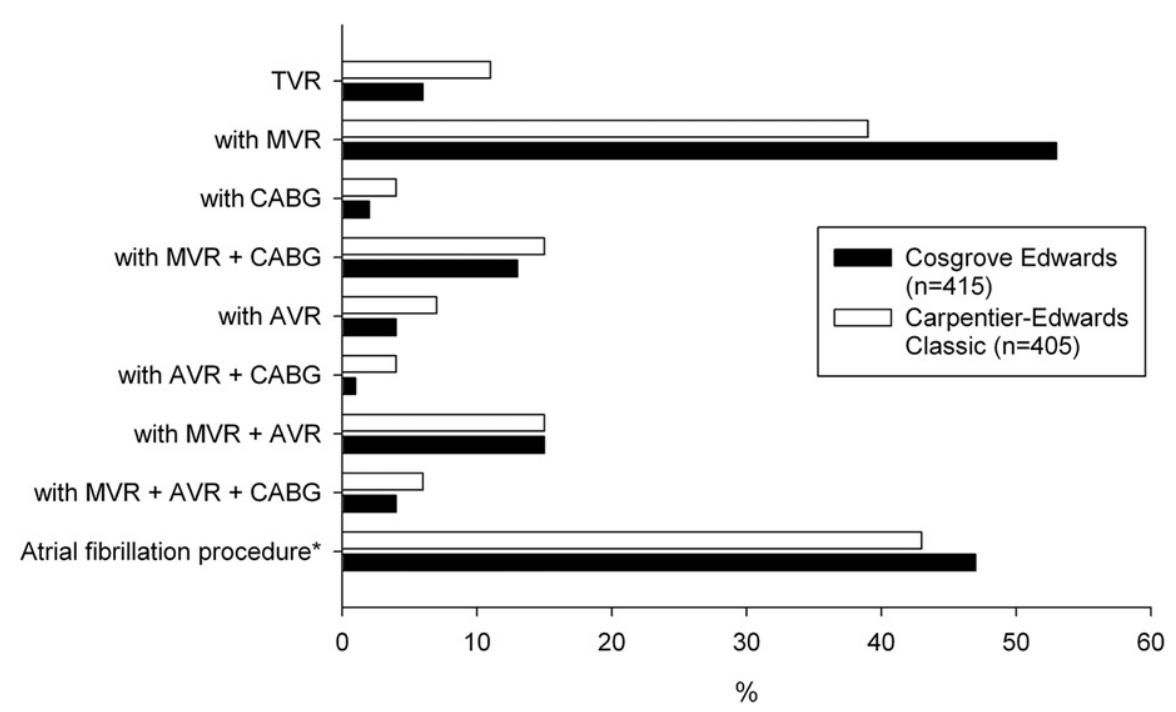

FIGURE 1. Surgical procedures performed. $T V R$, Tricuspid valve repair; $M V R$, mitral valve reconstruction or replacement; $C A B G$, coronary artery bypass grafting; $A V R$, aortic valve reconstruction or replacement. Asterisk indicates that an atrial fibrillation procedure is a concomitant procedure that is done in addition to the remaining procedures.

stroke, a total of 80 patients (Cosgrove-Edwards, 9.9\%; Carpentier-Edwards, $9.6 \% ; P=.7$ ) had postoperative low cardiac output syndrome, and 16 patients (Cosgrove-Edwards, $3.9 \%$; Carpentier-Edwards, $4.0 \% ; P=.9$ ) in each group underwent reoperation because of postoperative bleeding. Overall 30-day mortalities were $11.9 \%$ in the Cosgrove-Edwards group and $8.4 \%$ in the CarpentierEdwards $(P=.07)$.

Figure 4 shows the incidences of early postoperative ring dehiscence, as identified during the predischarge echocardiography. Patients who received a rigid ring had a 9-fold greater incidence of ring dehiscence than did patients who received a flexible band (Carpentier-Edwards, 8.7\%; Cosgrove-Edwards, $0.9 \% ; P<.001$ ). These ring dehiscences were exclusively located at the septal portion of the ring or band.

Table 3 shows the reasons for early severe residual TR after TV repair. In most cases, the regurgitation was central, whereas some cases were associated with transvalvular pacemaker leads. Logistic regression analysis revealed TV ring type to be the only significant risk factor for dehiscence (odds ratio, 10.7; 95\% confidence interval, $3.2-36.5 ; P<.001)$. As can be seen when examining the data in Table 3 and Figure 4, not all patients with ring dehiscence had severe TR. Ring dehiscence was the cause of severe TR in only 8 patients, and all such cases were found in the rigid ring group.

Figure 5 shows the freedom from TV reoperation during follow-up. After 5 years, the TV reoperation rates in both groups were less than $10 \%$. A total of 10 patients were reoperated on between 3 days and 4 years postoperatively because of recurrent severe TR (Cosgrove-Edwards, 3 patients; Carpentier-Edwards, 7 patients). For the 3 patients of the Cosgrove-Edwards group who required reoperation during follow-up, the causes were central insufficiency, restrictive leaflet motion, and tricuspid stenosis from annular pannus formation in 1 case each. For the 7 patients of the Carpentier-Edwards group requiring reoperation, the causes were ring dehiscence in 4 patients, central insufficiency in 2 patients, and restrictive leaflet motion in 1 patient. Among the 10 patients requiring repeated TV surgery, only 5 patients (Carpentier-Edwards, 3 patients;

TABLE 2. Perioperative patient characteristics

\begin{tabular}{lccc}
\hline & $\begin{array}{c}\text { All patients } \\
(\mathbf{n}=\mathbf{8 2 0})\end{array}$ & $\begin{array}{c}\text { Cosgrove-Edwards } \\
(\mathbf{n}=\mathbf{4 1 5})\end{array}$ & $\begin{array}{c}\text { Carpentier-Edwards } \\
\text { Classic (n=405) }\end{array}$ \\
\hline Operative time (min) & $233.6 \pm 70.2$ & $228.0 \pm 66.7$ & $239.5 \pm 73.2$ \\
Crossclamp time (min) & $87.9 \pm 38.7$ & $87.1 \pm 34.8$ & $88.6 \pm 42.3$ \\
Cardiopulmonary bypass time (min) & $156.0 \pm 109.4$ & $154.6 \pm 143.5$ & .019 \\
Preoperative tricuspid regurgitation grade & $2.3 \pm 0.6$ & $2.2 \pm 0.6$ & .58 \\
Postoperative tricuspid regurgitation grade & $0.7 \pm 0.6$ & $0.7 \pm 0.6$ & .71 \\
\hline
\end{tabular}

Data are mean \pm standard deviation. Cosgrove-Edwards, Cosgrove-Edwards annuloplasty system, Edwards Lifesciences LLC, Irvine, Calif; Carpentier-Edwards Classic, Carpentier-Edwards Classic annuloplasty ring, Edwards Lifesciences. 


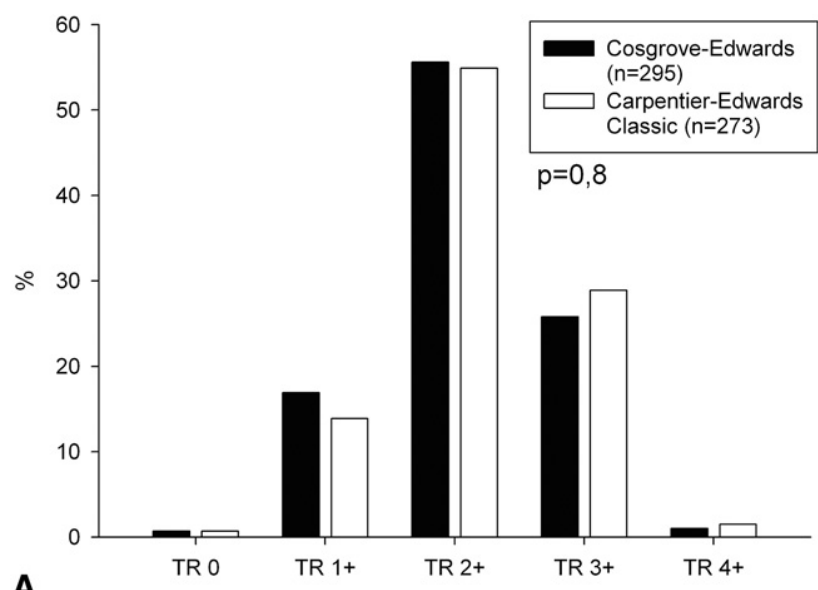

A

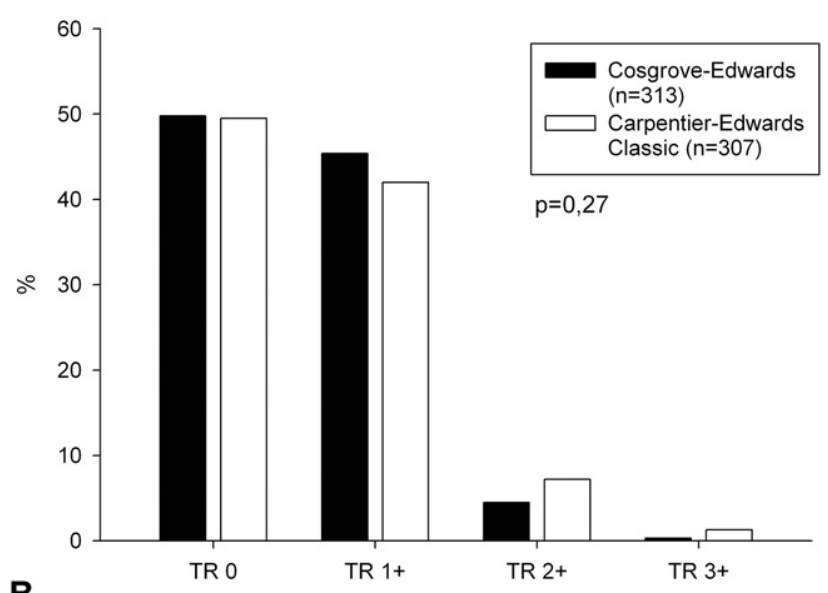

FIGURE 2. A, Preoperative grade of tricuspid regurgitation (TR). $\mathrm{B}$, Immediate postoperative grade of tricuspid regurgitation.

Cosgrove-Edwards, 2 patients) were reoperated on solely because of the TV, whereas the remaining patients had mitral valve insufficiency as the primary indication for surgery.

Figure 6 shows long-term survivals in both patient groups. Survival was lower in the Carpentier-Edwards group (Cosgrove-Edwards 5-year survival, 64.7\% \pm $4.4 \%$; Carpentier-Edwards 5-year survival, $60.3 \% \pm$ $4.6 \%$; log-rank $P=.053$ ).

\section{DISCUSSION}

We have shown in this study that although both rigid and flexible system provide acceptable results for TV repair, the use of a rigid ring significantly increases the risk of early annular dehiscence. To the best of our knowledge, the difference in incidence of ring dehiscence between these annuloplasty systems has not been described before and therefore requires further discussion.

Other investigators have compared the results of annuloplasty performed with rings or bands. McCarthy and

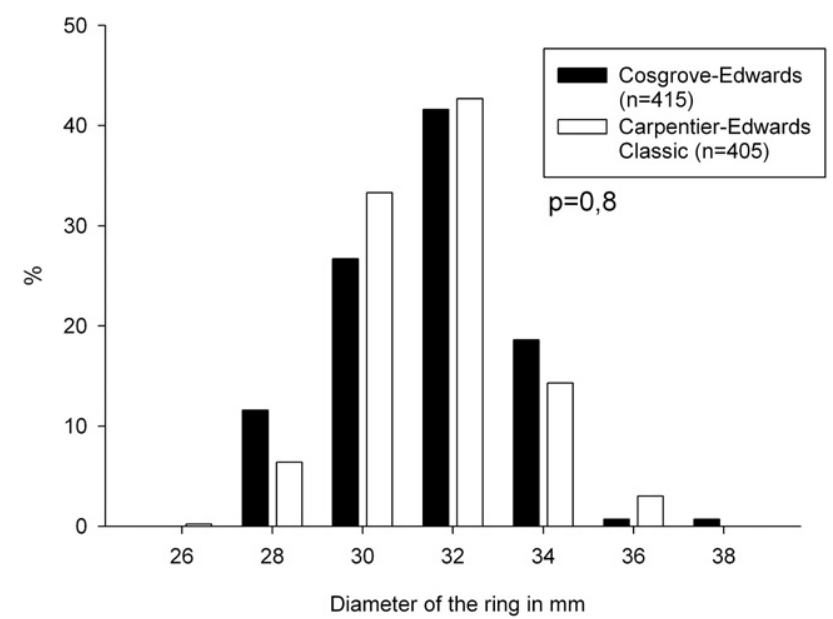

FIGURE 3. Manufacturer labeled size of implanted ring or band.

colleagues, ${ }^{2}$ for example, found residual TR ( $3+$ or $4+$ ) in $14 \%$ of patients early after TV repair. They did not, however, provide information on the causes of postrepair regurgitation. In our patient population, severe postoperative TR was rare, and annular ring dehiscence was the cause of TR in only a third of these patients. We can thus conclude that the occurrence of ring dehiscence in the early postoperative phase is not always associated with the occurrence of severe TR.

Irrespective of the early consequences of ring dehiscence, it is important to investigate the underlying mechanism. We discovered that ring dehiscence only occurred in the region of the septal annulus, as determined by echocardiography or recorded in the reoperative surgical notes. One contributing factor may be the experience of the surgeon; that is, the surgeon with less experience may shy away from taking deeper bites at the septal annulus close to the atrioventricular node for fear of atrioventricular block. If "shallow stitching"

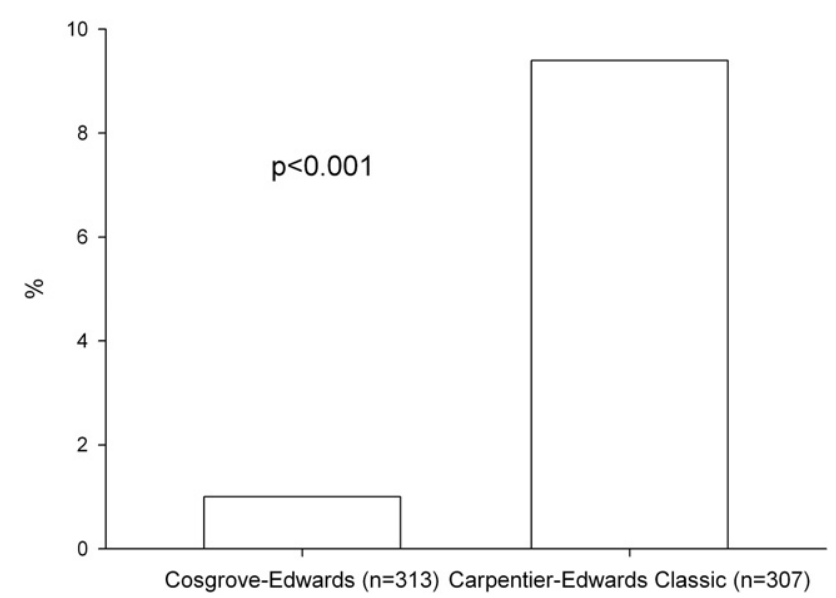

FIGURE 4. Frequency of ring or band dehiscence expressed as percentage of implanted rings or bands. 
TABLE 3. Reasons for postoperative tricuspid regurgitation greater than $2+$ on predischarge echocardiography

\begin{tabular}{lcc}
\hline & $\begin{array}{c}\text { Cosgrove-Edwards } \\
(\mathbf{n}=\mathbf{1 5})\end{array}$ & $\begin{array}{c}\text { Carpentier-Edwards } \\
\text { Classic }(\mathbf{n = 2 6})\end{array}$ \\
\hline $\begin{array}{l}\text { Central tricuspid } \\
\text { regurgitation }\end{array}$ & $10(66.7 \%)$ & $14(53.8 \%)$ \\
$\begin{array}{l}\text { Pacemaker } \\
\text { Ring dehiscence }\end{array}$ & $5(33.3 \%)$ & $4(15.4 \%)$ \\
$\begin{array}{l}\text { Ring dehiscence plus } \\
\text { pacemaker }\end{array}$ & 0 & $6(23.1 \%)$ \\
\hline
\end{tabular}

Data represent numbers and percentages of patients. Cosgrove-Edwards, CosgroveEdwards annuloplasty system, Edwards Lifesciences LLC, Irvine, Calif; CarpentierEdwards Classic, Carpentier-Edwards Classic annuloplasty ring, Edwards Lifesciences.

were responsible for ring dehiscence, however, then both annuloplasty systems should have torn out at the same rate.

Another possible explanation is that increased shearing forces are being experienced at the septal portion of the annulus, and that these shearing forces would be even higher when a rigid ring is used. This line of argument finds support in the studies addressing the dynamics of the native tricuspid annulus. ${ }^{14-16}$ There are significant changes in the tricuspid annular dimensions from systole to diastole, with a $19 \%$ change of annular circumference and a $30 \%$ change in the annular area. ${ }^{15}$ In addition, Ton-Nu and coworkers ${ }^{16}$ demonstrated that tricuspid dilatation occurs mainly in the free wall of the tricuspid annulus at the middle part of the anterior leaflet and extending to the septal fixation point of ring annuloplasty devices. Thus the area in which we found all ring dehiscences occurring corresponds

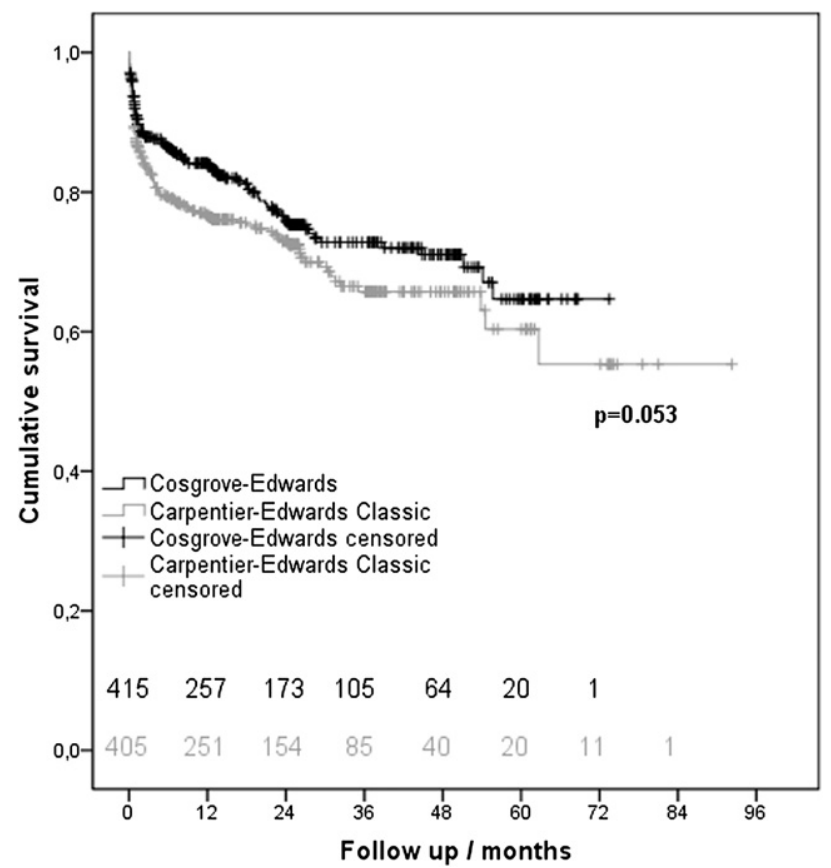

FIGURE 5. Postoperative survivals.

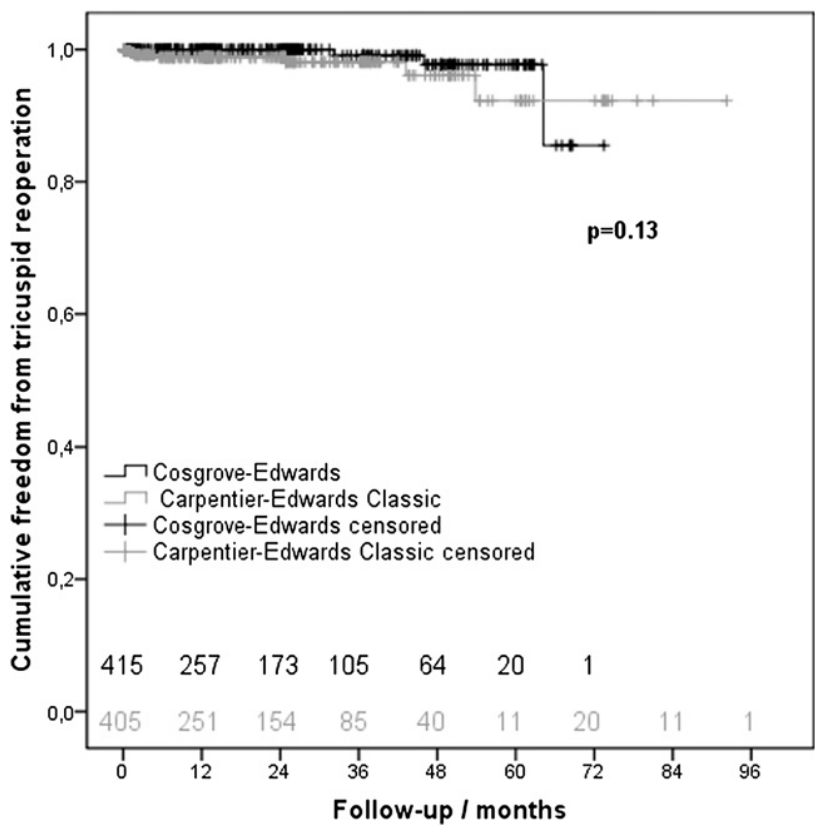

FIGURE 6. Postoperative freedoms from tricuspid-related reoperation.

to the end of the annular section that is most prone to dilatation. Taking these changes together with systolic-diastolic dynamics of tricuspid annular motion and the rigidity of the annuloplasty device, we conclude that greater forces may exist on the sutures attached to a rigid ring than on those attached to a flexible band, which may follow the natural motion of the tricuspid annulus more easily.

Our results appear to suggest that flexible bands are preferable to rigid rings. Others, however, have demonstrated better long-term durability of annuloplasty with rigid rings, ${ }^{2,12,13}$ and we did not assess the incidence of ring dehiscence in other rigid rings, including 3-dimensional annuloplasty systems. Finally, we were unable to obtain echocardiographic follow-up for our patients, and the use of freedom of reoperation and survival as end points may underestimate the frequency of recurrent severe TR.

We conclude that TV annuloplasty with a rigid ring increases the risk of early ring dehiscence. Both rigid and flexible systems, however, provide acceptable results in TV repair.

\section{References}

1. Dreyfus GD, Raja SG, John Chan KM. Tricuspid leaflet augmentation to address severe tethering in functional tricuspid regurgitation. Eur J Cardiothorac Surg. 2008;34:908-10.

2. McCarthy PM, Bhudia SK, Rajeswaran J, Hoercher KJ, Lytle BW, Cosgrove DM, et al. Tricuspid valve repair: durability and risk factors for failure. J Thorac Cardiovasc Surg. 2004;127:674-85.

3. Raja SG, Dreyfus GD. Surgery for functional tricuspid regurgitation: current techniques, outcomes and emerging concepts. Expert Rev Cardiovasc Ther. 2009;7:73-84.

4. Carpentier A, Relland J. Carpentier rings and tricuspid insufficiency. Ann Thorac Surg. 1979;27:95-6. 
5. Frater R. Tricuspid insufficiency. J Thorac Cardiovasc Surg. 2001;122:427-9.

6. Jeong DS, Kim KH. Tricuspid annuloplasty using the MC3 ring for functional tricuspid regurgitation. Circ J. 2010;74:278-83.

7. Filsoufi F, Salzberg SP, Coutu M, Adams DH. A three-dimensional ring annuloplasty for the treatment of tricuspid regurgitation. Ann Thorac Surg. 2006;81: 2273-7.

8. Rogers JH, Bolling SF. The tricuspid valve: current perspective and evolving management of tricuspid regurgitation. Circulation. 2009;119:2718-25.

9. Rivera R, Duran E, Ajuria M. Carpentier's flexible ring versus De Vega's annuloplasty. A prospective randomized study. J Thorac Cardiovasc Surg. 1985;89: 196-203.

10. Fukuda S, Gillinov AM, McCarthy PM, Matsumura Y, Thomas JD, Shiota T. Echocardiographic follow-up of tricuspid annuloplasty with a new threedimensional ring in patients with functional tricuspid regurgitation. J Am Soc Echocardiogr. 2007;20:1236-42.

11. Ghanta RK, Chen R, Narayanasamy N, McGurk S, Lipsitz S, Chen FY, et al. Suture bicuspidization of the tricuspid valve versus ring annuloplasty for repair of functional tricuspid regurgitation: midterm results of 237 consecutive patients. J Thorac Cardiovasc Surg. 2007;133:117-26.
12. Navia JL, Nowicki ER, Blackstone EH, Brozzi NA, Nento DE, Atik FA, et al. Surgical management of secondary tricuspid valve regurgitation: annulus, commissure, or leaflet procedure? J Thorac Cardiovasc Surg. 2010;139:1473-82.e5.

13. Tang GH, David TE, Singh SK, Maganti MD, Armstrong S, Borger MA. Tricuspid valve repair with an annuloplasty ring results in improved long-term outcomes. Circulation. 2006;114(1 Suppl):I577-81.

14. Fukuda S, Saracino G, Matsumura Y, Daimon M, Tran H, Greenberg NL, et al. Three-dimensional geometry of the tricuspid annulus in healthy subjects and in patients with functional tricuspid regurgitation: a real-time, 3-dimensional echocardiographic study. Circulation. 2006;114(1 Suppl):I492-8.

15. Tei C, Pilgrim JP, Shah PM, Ormiston JA, Wong M. The tricuspid valve annulus: study of size and motion in normal subjects and in patients with tricuspid regurgitation. Circulation. 1982;66:665-71.

16. Ton-Nu TT, Levine RA, Handschumacher MD, Dorer DJ, Yosefy C, Fan D, et al Geometric determinants of functional tricuspid regurgitation: insights from 3-dimensional echocardiography. Circulation. 2006;114:143-9.

17. Fehske W, Omran H, Manz M, Köhler J, Hagendorff A, Lüderitz B. Color-coded Doppler imaging of the vena contracta as a basis for quantification of pure mitral regurgitation. Am J Cardiol. 1994;73:268-74. 